\title{
Effect of Silver Nanoparticles (AgNps) Produced by an Endophytic Fungus Fusarium Semitectum Isolated from a Medicinal Plant Withania Somnifera (Ashwagandha) on Seed Germination
}

\author{
Ashish Kumar Singh, Vandana Rathod*, Dattu Singh, Jasmine Mathew, \\ Prema Kulkarni \\ Department of P.G. Studies and Research in Microbiology, Gulbarga University, \\ Kalaburagi, Karnataka, India \\ *drvandanarathods@gmail.com, ashishsc89@gmail.com
}

\begin{abstract}
AgNps were synthesized from the Endophytic fungus Fusarium semitectum isolated from healthy leaves of a medicinal plant Withania somnifera (Ashwagandha). Characterization of AgNps by UV-Vis showed a maximum absorption peak at 422nm. TEM revealed AgNps to be smaller in size, spherical in shape from 1220nm. Different concentration of AgNps was tested against germination of Mungbean, Pigeon Pea and Chickpea seeds. Percent seed germination, root and shoot length of all the three seeds were measured. The Germination index (G.I) of Mungbean and Pigeon Pea seeds was maximum 123.33 and 117.64 with $200 \mu$ of AgNps and Cent percent seed germination in Mungbean seeds while it was $58.3 \%$ in Pigeon Pea. The average root and shoot length was maximum $4.6 \mathrm{~cm}$ and $4.7 \mathrm{~cm}$ with $100 \mu \mathrm{l}$ of AgNps in Mungbean whereas, shoot length was $4 \mathrm{~cm}$ at $200 \mu \mathrm{l}$ and root length was $4.4 \mathrm{~cm}$ at $100 \mu \mathrm{l}$. In case of Chickpea the G.I was maximum 46.51 with maximum \% seed germination of $78.5 \%$ and shoot length of $2 \mathrm{~cm}$ with maximum root length of $4.9 \mathrm{~cm}$ at $100 \mu \mathrm{lof}$ AgNps. All these results reveal that 100 and 200 $\mu$ l of AgNps can enhance root and shoot germination while, higher concentration of AgNps showed Phytotoxicity revealing that dose dependency will have good effect on overall plant growth.
\end{abstract}

\section{INTRODUCTION}

Application of nanotechnology is now available in various fields of science due to the extensive research being undertaken throughout the world. Nanotechnology has the potential to revolutionize agriculture with new tools to enhance the ability of plants to absorb specific required nutrients (Savithramma N et al., 2012). With the advent of nanotechnology AgNps have been applied in many fields such as medical, industrial, dairy products and also in agriculture. AgNps may be released into the environment by several routes, including during their synthesis, incorporation of AgNps into other goods, and recycling or disposal of these goods and AgNps Experts feel that the potential benefits of nanotechnology for agriculture, food, fisheries and aquaculture need to be balanced against concerns for the soil, water, and environment and the occupational health of workers. Raising awareness of nanotechnology in the agri-food sector, including feed and food ingredients, intelligent packaging and quick-detection systems, is one of the keys to influencing consumer acceptance.

There have been different and often conflicting reports on the absorption, translocation, accumulation, biotransformation and toxicity of nano particles in various plant species. Recent studies have reported that a plant's response to AgNps enhancement or inhibition of growth, depends on the AgNp dosage. Exposure to specific concentration of AgNps could enhance plant growth compared with non-exposed plants, whereas higher and lower concentrations could effect plant growth. (R. Kaveh et al., 2013 and H.Qian et al, 2013). A lot of studies have been reported on positive and negative effects of nano particles on higher plants. Due to its variable shape and size, it is difficult to predict the positive or negative effect and its mode of action in the environment and within living systems. (M.Holsapple et al., 2005)

On the basis of only a handful of toxicological studies, concerns have arisen regarding the safety of nano materials, researchers and companies will need to prove that these nanotechnologies do not have more of a negative impact on the environment. Agri-food nanotechnology is multidisciplinary in 
nature. Nanotechnology application to the agriculture and food sectors is relatively recent. compared with its use in drug delivery and pharmaceuticals. Nanotechnology has the potential to protect plants, monitor plant growth, detect plant and animal diseases, increase global food production, enhance food quality, and reduce waste for "sustainable intensification"( Locke J.M. et al, 2000) We at our laboratory, made an attempt for employing nano particles in Agri by conducting studies on effect of AgNps on seed germination. Our results of exposure of AgNps to Mung bean, Pigeon Pea and Chickpea seeds have shown both positive and negative effect on seed germination, root and shoot growth

\section{MATerials AND MethodS}

\section{Isolation of Endophytic Fungi}

The isolation of endophytic fungus was carried out following the procedure of Ashish et al., (2015). Healthy leaves of Withania somnifera (Ashwagandha) were collected from Department of Botany. Gulbarga University Kalaburagi. washed several times with tap water followed by the Surface sterilization was done by immersing the leaves into a sequence of solvents finally rinsed with sterilized double distilled water, these cut leaves were dried with the help of blotting paper and inoculated onto the plates containing Potato Dextrose Agar (PDA), the inoculation was done considering that the cut surface of the leaf explant was half pierced into the medium, incubated at $28^{\circ} \mathrm{C}$ for 6-8 days for the growth of Endophytic fungal colonies out of the leaf segment. Fungus which grew out of the explant based on its morphological and reproductive characters using standard identification manual was identified and used for further study.

\section{Biological Synthesis of Silver Nanoparticles}

The endophytic fungus Fusarium semitectum was screened for the biosynthesis of AgNps. A $250 \mathrm{ml}$ Erlynmeyer flask containing $100 \mathrm{ml}$ of MGYP medium (3g Malt extract, $3 \mathrm{~g}$ Yeast extract, $5 \mathrm{~g}$ Peptone, Distilled water $1000 \mathrm{ml}$ ) was incubated at $28^{\circ} \mathrm{C}$ for 2 days in static position. The fungal mycelia obtained was separated by filtering through What man filter paper No.1 and then repeatedly washed with distilled water Further, the biomass was again suspended into the flask containing double distilled water and harvesting the fungal filtrate through What man filter paper No 1, which was then treated with $1 \mathrm{mM}$ Silver nitrate $\left(\mathrm{AgNo}_{3}\right)$ solution and incubated at $28^{\circ} \mathrm{C}$ for reduction $\left(\mathrm{Ag}^{+}\right.$to $\left.\mathrm{Ag}^{0}\right)$ and observed for the color change from pale white to brown, which is an indication for the production of AgNps

\section{Characterization of Silver Nanoparticles}

\section{UV-Vis Spectroscopy}

The synthesized AgNps solution was observed for the change in color visually of the mycelia free filtrate when treated with $1 \mathrm{mM}$ silver nitrate solution and was confirmed by sampling the reaction mixture at regular intervals and the absorption maxima was scanned by UV-Vis spectra at the wavelength between 350 to $500 \mathrm{~nm}$.

\section{Transmission Electron Microscopy (TEM)}

The morphology of biosynthesized AgNps was studied using TEM technique (Hitachi H-7500). A drop of biosynthesized AgNps solution was placed on a carbon coated copper grids and kept overnight under vaccum desiccation and dried. The sample was loaded onto a specimen holder. Transmission electon micrographs of samples were taken.

\section{Seed Germination Experiment}

Mungbean, Pigeon Pea and Chickpea seeds were collected from local market of Kalaburagi city, Karnataka. These seeds were several times washed with tap water to remove the dirt and adherent particles, surface sterilized followed by washing with distilled water then some of the seeds were dipped in distilled water (Control) and in the AgNps solution of 3 different concentrations like 100, 200 and $300 \mu \mathrm{l}$. The seeds were treated with the above mentioned concentrations and subsequently transferred to petridishes containing one piece of filter paper about 6-7 seeds were evenly placed in the petridishes and were allowed to germinate on lab bench at room temperature. After 5 days of growth the root and shoot length were measured and recorded. The germination index and \% seed germination were determined by using the formula given below 
Effect of Silver Nanoparticles (AgNps) Produced by an Endophytic Fungus Fusarium Semitectum Isolated from a Medicinal Plant Withania Somnifera (Ashwagandha) on Seed Germination

$\begin{array}{rlr}\% \text { Seed Germination }= & \begin{array}{c}\text { No. of germinated seeds } \\$\cline { 2 - 3 } \text {$Germination Index (G.I) }=\end{array} & \begin{array}{c}\text { No. of Inoculated seeds } \\ \text { Average Root length }\end{array} \\ \frac{\text { Average Shoot length }}{\text { x } 100}\end{array}$

\section{RESULTS AND DISCUSSION}

\section{Isolation of Endophytic Fungi and Biosynthesis of AgNps}

Endophytic fungus was grown out of the leaf segment of Withania somnifera (Ashwagandha) after 7 days of incubation on PDA plates. The fungus was subcultured and identified as Fusarium semitectum. based on the morphological and microscopic observations at Agharkar Research Institute, Pune. The Endophytic fungus Fusarium semitectum, isolated was used for the production of AgNps. The extracellular filtrate was treated with $1 \mathrm{mM} \mathrm{AgNo}_{3}$ solution and the reduction was indicated by the change in color from pale white to brown indicating the production of AgNps and later was confirmed by UV-Vis spectrophotometric analysis (Fig 1a \& b)

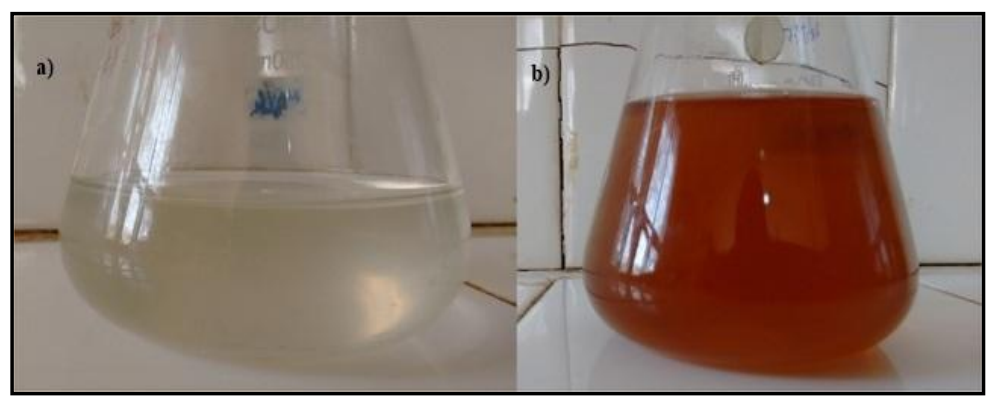

Fig 1a. Enzyme filtrate of Endophytic fungus, Fusarium semitectum.

Fig 1b. Treatment with $1 \mathrm{mM}$ silver nitrate solution changes the color to reddish brown

\section{UV-Vis Spectroscopy}

UV-Vis spectrophotometric analysis was carried out for the AgNps produced using Endophytic fungus Fusarium semitectum, with the maximum absorbance peak at $422 \mathrm{~nm}$ was observed (Fig 2). The values lie between 300 to $500 \mathrm{~nm}$ which confirms the production of AgNps. Chandrasekhar et al., (2014) reported the production of AgNps from the fungal extract of the Endophytic fungus, Penicillium nodositatum with the maximum absorbance peak at $420 \mathrm{~nm}$, Dattu et al., (2013), reported the production of AgNps with the maximum absorption peak by Surface Plasmon Resonance (SPR) at $420 \mathrm{~nm}$ from the fungal extract of Penicillium sp., an Endophytic fungus isolated from Curcuma longa (turmeric). Similarly other researchers Shivaraj et al., (2014) also reported single peak with a maximum absorbance at $416 \mathrm{~nm}$ corresponding to the SPR of AgNps. Our results correlate with the above said authors.

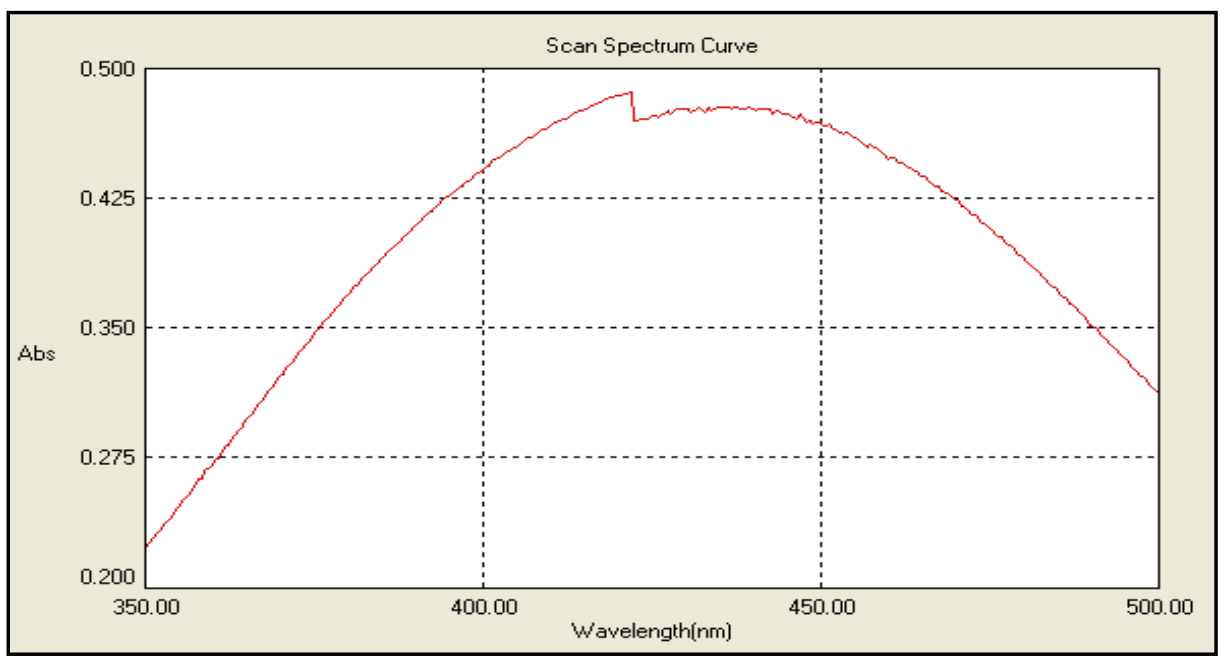

Fig 2. UV-Vis spectra of AgNps synthesized by the Endophytic fungus Fusarium semitectum 


\section{Transmission Electron Microscopy (TEM)}

TEM determines the morphology and size details of the synthesized AgNps. Size and shape of the nanoparticles were recorded and found to be well dispersed, small in size and spherical in shape ranging from 12-20 nm (Fig 3). Prema et al., (2014), reported spherical shaped AgNps with the size ranging from 20 to $35 \mathrm{~nm}$ produced by extracellular filtrate of A.terreus and Dattu et al., (2013), reported well dispersed spherical shaped nanoparticles with a size range of 25-30 nm using extracellular filtrate of Endophytic fungus Penicillium sp., Kirthika et al., (2014) reported the spherical shaped AgNps with a size approximately $25 \mathrm{~nm}$ from aqueous plant extract of T.chebula. Surprisingly the size of the nanoparticles produced by our organism appears to be the smallest, which may show good effects in various fields.

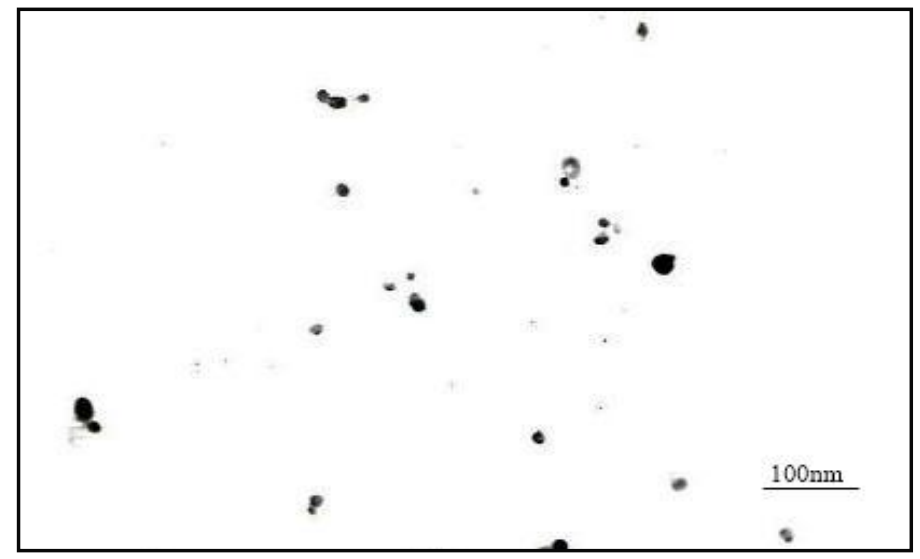

Fig 3. TEM showing well dispersed AgNps by Endophytic fungus Fusarium semitectum.
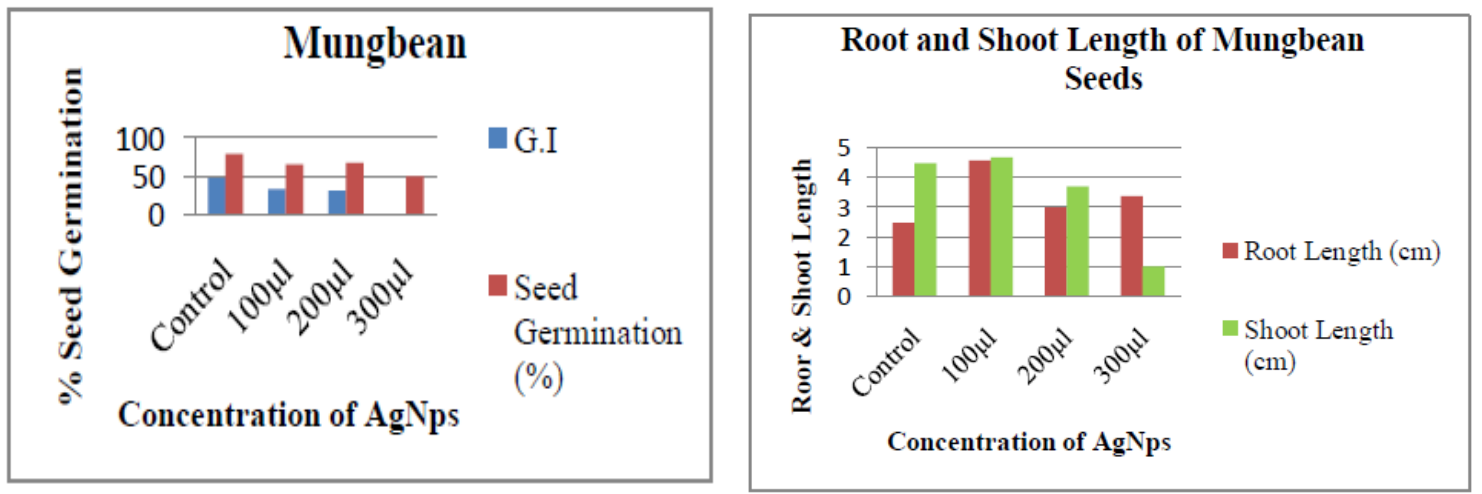

Graph 1 \& 2. Seed Germination (\%), Root and Shoot index of Mungbean Seeds

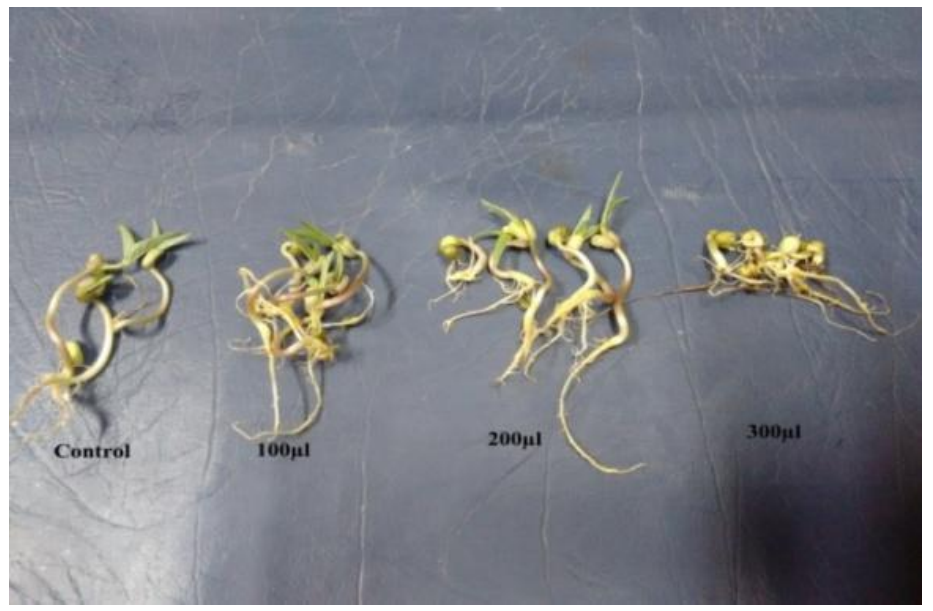

Fig 4. Germinated Mungbean Seeds treated with different concentrations of AgNps 
Effect of Silver Nanoparticles (AgNps) Produced by an Endophytic Fungus Fusarium Semitectum Isolated from a Medicinal Plant Withania Somnifera (Ashwagandha) on Seed Germination
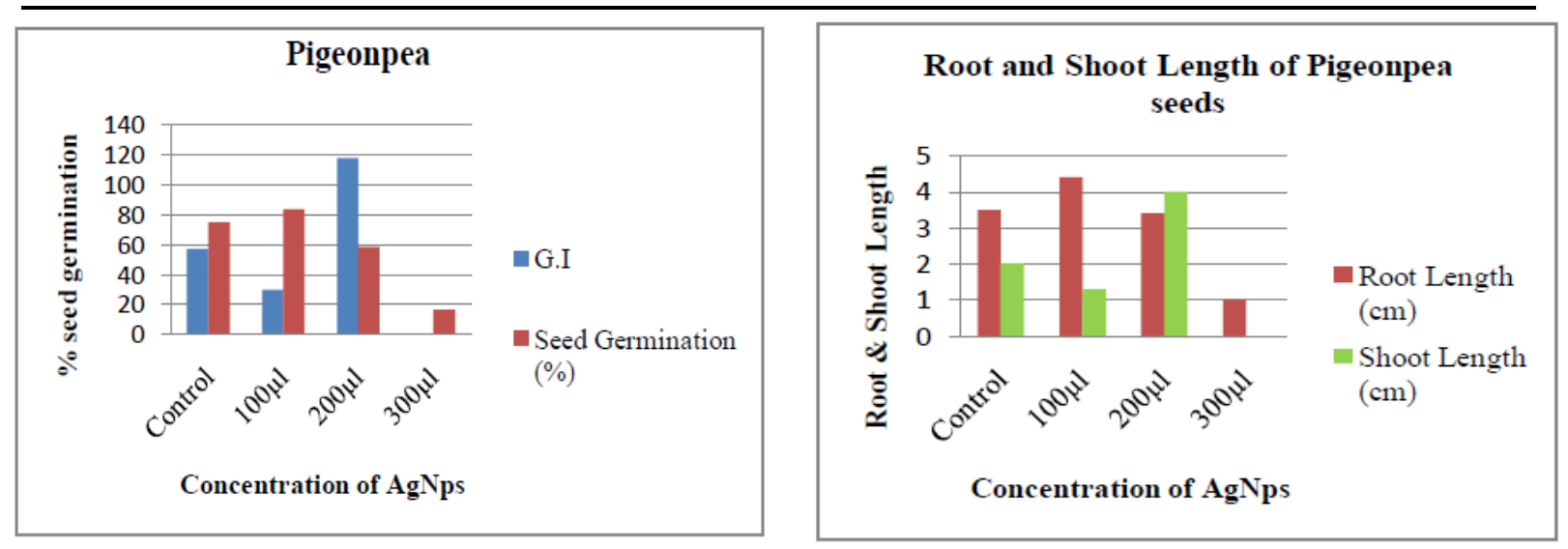

Graph 3 \& 4. Seed Germination (\%), Root and Shoot index of Pigeonpea Seeds

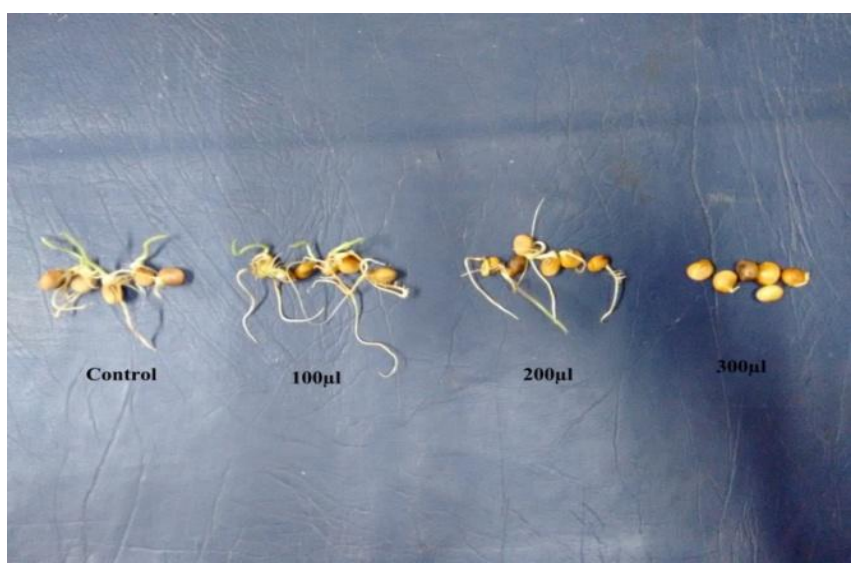

Fig 5. Germinated Pigeonpea Seeds treated with different concentrations of AgNps
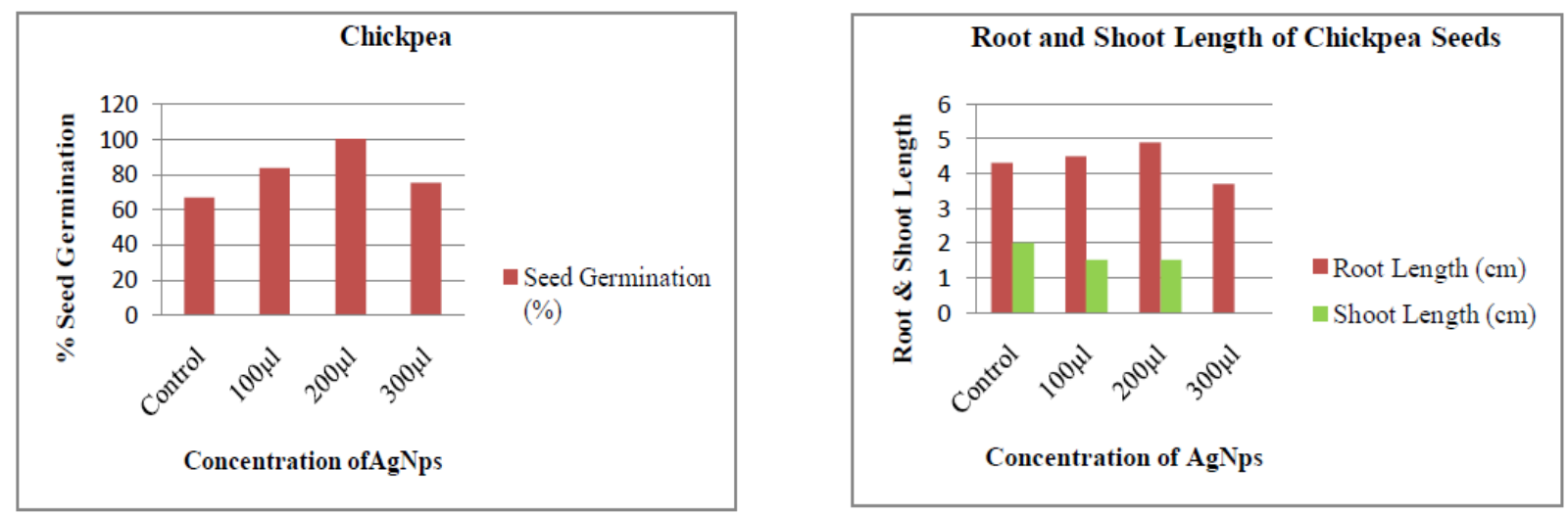

Graph 4 \& 5. Seed Germination (\%), Root and Shoot index of Chickpea Seeds

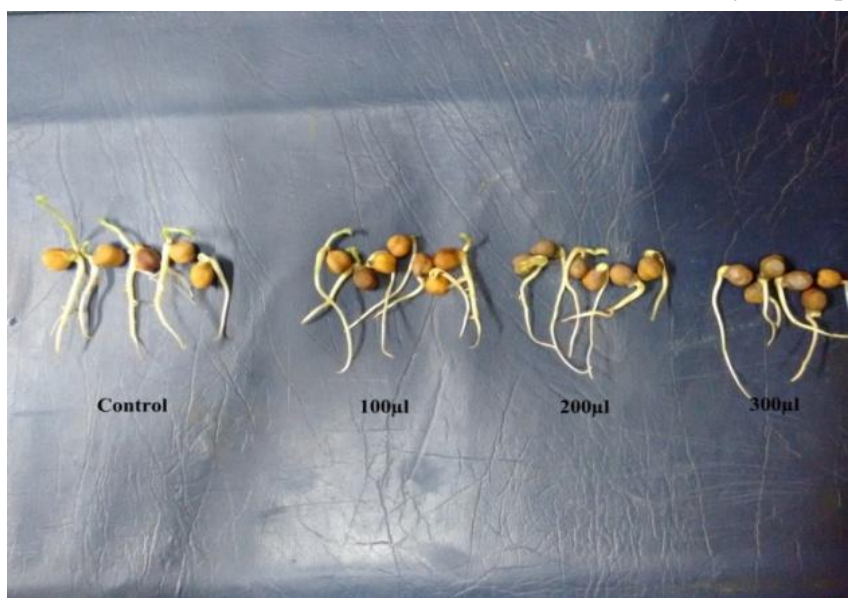

Fig 6. Germinated Chickpea Seeds treated with different concentrations of AgNps 


\section{Seed Germination Experiment}

From the figures the Percent (\%) seed germination, growth index, root and shoot germination in $\mathrm{cms}$ were calculated. In case of Mungbean, Pigeon Pea and Chickpea seeds were analysed. The results were so encouraging that from the figures it is clearly evident that AgNps have shown very good effect on the $5^{\text {th }}$ day of germination.

Effect of AgNps on Mungbean Seeds: The G.I index of Mungbean seeds were maximum 123.33 with $200 \mu 1$ of AgNps while with same concentration \% seed germination was cent percent whereas the average root and shoot length were maximum, i.e $4.6 \mathrm{~cm}$ and $4.7 \mathrm{~cm}$ respectively with $100 \mu 1 \mathrm{of} A \mathrm{gNps}$ concentration (Fig 4, Graph1\&2)

Effect of AgNps on Pigeon Pea: The G.I index of pigeonpea were again maximum 117.64 with $200 \mu 1$ of AgNps which was same as that of Mungbean seeds while, the \% seed germination was $58.3 \%$ when root length and Shoot length were compared the shoot length was maximum $4.0 \mathrm{~cm}$ at $200 \mu 1$ while, the root length was maximum $4.4 \mathrm{~cm}$ at $100 \mu \mathrm{l}$ which reveals that a concentration between 100 and $200 \mu 1$ of AgNps are not toxic beyond the concentration of $200 \mu 1$ i.e $300 \mu 1$ the germination index was 'nil' and the $\%$ seed germination index was minimum i.e 16.6 and with minimum root length of $1 \mathrm{~cm}$ and no shoot length at all (Fig 5, Graph 3\&4)

Effect of AgNps on Chickpea: Similarly, the Chickpea results depicts that though the G.I was maximum i.e 46.51 with maximum \% germination of 78.5and shoot length of $2 \mathrm{~cm}$ but amongst the concentration of AgNps used 100 $\mu 1$ showed a maximum G.I of 33.33 with the \% seed germination of $66.6 \%$ with maximum root length of $4.9 \mathrm{~cm}$ even higher than the control. The shoot length 0 $1.5 \mathrm{~cm}$ each was observed in both $100 \& 200 \mu 1$ of AgNps whereas the G.I and the shoot length was 'nil' with $300 \mu 1$ showing lowest root length of 3.7 with lowest $\%$ seed germination of $50 \%$. (Fig 6, Graph 5\&6)

Lifen wang et al., (2015) reported the germination rate of R.sativus ses ranged from 90 to $97 \%$ and no significant difference between control, AgNps treatment. They reported that AgNps do not have accurate toxic effect on R.sativus seed germination. While Lin \& xing (2007) showed that nanoparticles had less effect on seed germination compared to seedling growth in R.sativus

The increasing use of nano particles in daily products is a great concern, particularly when the positive and negative impacts of nano particles on nano particles on environment are not known Zainab et al., (2015) investigating the impact of AgNps reported that the highest germination \% $(73.33 \%)$ and the highest germination rates ( 1.59 seeds/day) for watermelon were recorded at $2 \mathrm{mg} / \mathrm{ml}$ AgNps for zucchini plants highest germination \% (86.67 \& 90\%) and highest germination rates $(1.68$ $\& 1.66$ seeds/day) were recorded at $0.5 \& 2.5 \mathrm{mg} / \mathrm{ml}$ of AgNPs while in corn seeds the highest germination rate was 6.5 seeds/day with $1.5 \mathrm{mg} / \mathrm{ml}$ of AgNps. They reported that among three plant sps. Zucchini seeds, the germination time of which increased significantly at 1.5 and $2.5 \mathrm{mg} / \mathrm{ml}$ of AgNps translating to later germination than untreated plants.

Reports reveal that it is probable that nanoparticles penetrate the seed coat and exert a beneficial effect on the process of seed germination by increasing water absorption by seeds (zheng et al., 2005). They also increase nitrate reductase enzyme levels, increase the seed abilities to absorb and utilize fertilizer, promote seed antioxidant systems (Lu et al., 2002), reduce oxidative stress by reducing $\mathrm{H}_{2} \mathrm{O}_{2}$ superoxide radicals and malonyldialdehyde content and increase the activities of some enzymes such as superoxide dismutase, ascorbate peroxidise, guaiacol peroxidase and catalase All these studies express that the biocompatibility of AgNps can be determined and the potential agricultural applications for nanoparticles in crop improvement and food production can be judged.

\section{CONCLUSION}

Use of nanoparticles is leading to the progress of a range of inexpensive applications for enhanced plant growth. Applications of nanomaterials can encourage earlier plant germination and improve plant productivity. (Reyhanch azimi et al., 2013). AgNps have been known as a kind of antibiotics. These particles provide protections against fungi and bacteria present in the seeds germination rate, root and shoot elongation as a rapid phytotoxicity test method posses several advantages such as sensitivity, cost effectiveness and stability for unstable chemicals our results revealed that a higher concentration of $300 \mu \mathrm{l}$ had no significant effect, rather showed toxic effect on both root and shoot germination while a concentration of $200 \mu 1$ increased the rate of germination compared to control hence AgNps not only can be used as test material to reveal their non toxicity mechanism in plants and genetic imbalance but also for determining their biocompatibility and identifying their potential agriculture applications in crop improvement and food productivity. 


\section{REFERENCES}

[1] Savithramma N, Ankanna S, Bhumi G. Effect of nanoparticles on seed germination and seedling growth of Boswellia ovalifoliolata an endemic and endangered medicinal tree taxon. Nano Vision. 2012; 2(1):2.

[2] Kaveh R, Li YS, Ranjbar S, Tehrani R, Brueck CL, Van Aken B. Changes in Arabidopsis thaliana gene expression in response to silver nanoparticles and silver ions. Environmental science \& technology. 2013 Sep 9; 47(18):10637-44.

[3] Qian H, Peng X, Han X, Ren J, Sun L, Fu Z. Comparison of the toxicity of silver nanoparticles and silver ions on the growth of terrestrial plant model Arabidopsis thaliana. Journal of Environmental Sciences. 2013 Sep 30; 25(9):1947-56.

[4] Holsapple MP, Farland WH, Landry TD, Monteiro-Riviere NA, Carter JM, Walker NJ, Thomas $\mathrm{KV}$. Research strategies for safety evaluation of nanomaterials, part II: toxicological and safety evaluation of nanomaterials, current challenges and data needs. Toxicological Sciences. 2005 Nov 1; 88(1):12-7.

[5] Locke JM, Bryce JH, Morris PC. Contrasting effects of ethylene perception and biosynthesis inhibitors on germination and seedling growth of barley (Hordeum vulgare L.). Journal of Experimental Botany. 2000 Nov 1; 51(352):1843-9.

[6] Singh AK, Rathod V, Dattu Singh SN, Kulkarni P, Mathew J, ul Haq M. Bioactive silver nanoparticles from endophytic fungus Fusarium sp. isolated from an ethanomedicinal plant Withania somnifera (Ashwagandha) and its Antibacterial Activity. International Journal of Nanomaterials and Biostructures. 2015; 5(1):15-9.

[7] Manjunath H, Chandrashekhar. J and Raju N, Biogenic synthesis of silver nano particles using endophytic fungi Penicillium nodositatum and its antibacterial activity. J. Chem. Pharm. Res., 2014; 6(8): 112-117.

[8] Singh D, Rathod V, Ninganagouda S, Herimath J, Kulkarni P. Biosynthesis of silver nanoparticle by endophytic fungi Pencillium sp. isolated from Curcuma longa (turmeric) and its antibacterial activity against pathogenic gram negative bacteria. Journal of Pharmacy Research. 2013 May 31; 7(5):448-53.

[9] Ninganagouda S, Rathod V, Singh D, Hiremath J, Singh AK, Mathew J. Growth kinetics and mechanistic action of reactive oxygen species released by silver nanoparticles from Aspergillus niger on Escherichia coli. BioMed research international. 2014 Jun 16; 2014.

[10] Kulkarni P, Rathod V, Hiremath J, Ninganagouda S. Biosynthesis and Characterization of Silver Nanoparticles from Aspergillus Terreus and its Antibacterial Efficacy against VRSA Strains. International Journal of Engineering. 2014 Jun;3(6).

[11] Kirthika P, Dheeba B, Sivakumar. Plant mediated synthesis and characterization of silver nanoparticles. International Journal of Pharmacy and Pharmaceutical Sciences. 2014 Sep 1;6(8).

[12] Lifen Wang, Juzhen Zhu, Qiuyun Wu, Yinghong Huang. Effects of Silver Nanoparticles on Seed Germination and Seedling growth of Radish (Raphanus sativus L.). International conference on Civil, Materials and Environmental Sciences (CMES 2015).

[13] Corral-Diaz B, Peralta-Videa JR, Alvarez-Parrilla E, Rodrigo-García J, Morales MI, OsunaAvila P, Niu G, Hernandez-Viezcas JA, Gardea-Torresdey JL. Cerium oxide nanoparticles alter the antioxidant capacity but do not impact tuber ionome in Raphanus sativus (L). Plant Physiology and Biochemistry. 2014 Nov 30; 84:277-85.

[14] Almutairi ZM, Alharbi A. Effect of Silver Nanoparticles on Seed Germination of Crop Plants. Agricultural and Biosystems Engineering. 2015 May 5; 2(6).

[15] Zheng L, Hong F, Lu S, Liu C. Effect of nano-TiO2 on strength of naturally aged seeds and growth of spinach. Biological trace element research. 2005 Apr 1; 104 (1):83-91.

[16] Lu C, Zhang C, Wen J, Wu G, Tao M. Research of the effect of nanometer materials on germination and growth enhancement of Glycine max and its mechanism. Soybean Science. 2002 Dec; 21(3):168-71.

[17] Azimi R, Feizi H, Hosseini MK. Can bulk and nanosized titanium dioxide particles improve seed germination features of wheatgrass (Agropyron desertorum). Notulae Scientia Biologicae. 2013 Jul 1; 5(3):325. 